\title{
Editorial \\ Editorial—Physical Modelling in Hydraulics Engineering
}

\author{
Enrique Peña $*$ and Jose Anta *(D) \\ Water and Environmental Engineering Research Team (GEAMA), Civil Engineering School, \\ Universidade da Coruña, Elviña, 15071 A Coruña, Spain \\ * Correspondence: enrique.penag@udc.es (E.P.); jose.anta@udc.es (J.A.)
}

Citation: Peña, E.; Anta, J. Editorial-Physical Modelling in Hydraulics Engineering. Water 2021, 13, 2317. https://doi.org/10.3390/ w13172317

Received: 16 July 2021

Accepted: 18 August 2021

Published: 24 August 2021

Publisher's Note: MDPI stays neutral with regard to jurisdictional claims in published maps and institutional affiliations.

Copyright: (c) 2021 by the authors. Licensee MDPI, Basel, Switzerland. This article is an open access article distributed under the terms and conditions of the Creative Commons Attribution (CC BY) license (https:// creativecommons.org/licenses/by/ $4.0 /)$.
Laboratory experiments and field works play a crucial role in hydraulic research, development, and design as many hydraulic processes elude analytical formulation or, at least for the time being, are not readily nor accurately reproducible with numerical simulations [1]. In recent years, the application of physical modeling in hydraulic engineering has experienced increasing progress due to several factors, such as (i) the development of new large-scale models, which allows analyzing and simulating different processes in controlled environments under close-to-reality conditions; (ii) the adoption of new measurement tools, such as imaging techniques or the application of low-cost technologies; and (iii) a change in the vision of hydraulic engineering that is now more closely connected with other areas of knowledge linked to water quality, ecosystemic services or the social perception of traditional engineering works. These factors, together with other societal challenges such as climate change, population growth or the digitalization of the water sector have led to a paradigm shift in the development of physical models in the field of hydraulic engineering. However, highly specialized state-of-the-art instrumentation and physical scale models are costly and require the collaboration of multi-sectorial research teams [2]. To ensure sustainability and avoid the duplication of efforts, collaboration between end users and research institutions can be enhanced through the establishment of multidisciplinary collaborative programs as the EU INFRAIA programs, with examples such as the HYDRALAB/HYDRALAB+ [3] research infrastructure networks in the field of marine and coastal research, or the Co-UDlabs [4] network in urban drainage systems.

The aim of this Special Issue is thus to publish the latest advances and developments concerning physical modeling in hydraulics engineering. This Special Issue contains contributions to the physical and numerical modeling of hydraulics structures, such as dam stilling basing [5-7], stepped spillways [8], free falling jets [9] and vortex shaft drops [10]. The development of traditional [11] and novel $[12,13]$ modelling approaches in river engineering are also covered in the Special Issue. Furthermore, contributions in the field of coastal structures and port engineering [14,15], offshore structures [16], and the environmental design of brine discharges [17] are presented in the Special Issue. Other topics covered in the Special Issue are related with pressurized pipe distribution [18-20] and urban drainage [21-23] systems. Selected highlights from each contribution are summarized as follows:

The paper "Experimental Characterization of the Hydraulic Jump Profile and Velocity Distribution in a Stilling Basin Physical Model" [5] analyses the free surface profile and the velocity distribution of the hydraulic jump in a typified USBR II stilling basin using a novel time-of-flight camera and a traditional Pitot tube. The results of the study suggest that a satisfactory representation of the free surface and other related hydraulic jump characteristics can be successfully obtained using the time-of-flight camera. Pitot tube equipment presents some limitations to determine velocity profiles in certain regions with a high density of air bubbles.

The article "Pressure Fluctuations in the Spatial Hydraulic Jump in Stilling Basins with Different Expansion Ratio" [6] analyses the role of pressure fluctuations in a rectangular stilling basin with a range of approaching Froude numbers and channel expansion ratios. 
The pressure fluctuations showed a clear dependence of Froude number and the distance from the toe of the jump. The authors propose a range of distances to reinforce the bed of the stilling basing to avoid structural damages caused by maximum pressure fluctuations.

The paper "Numerical Study of Fluctuating Pressure on Stilling Basin Slab with Sudden Lateral Enlargement and Bottom Drop" [7] uses large-eddy simulation (LES) and the TruVOF method to simulate a stilling basin slab physical model. The article provides a research method of combining quantitative analysis of the influencing factors (fluctuating velocity, velocity gradient, and fluctuating vorticity) and qualitative analysis of the distribution of fluctuating pressure in the swirling zone and in the impinging zone of the basin.

The article "Experimental and Numerical Study of the Effects of Geometric Appendance Elements on Energy Dissipation over Stepped Spillway" [8] deals with the influence of geometric appendance elements on the steps and its impact on the energy dissipation performances, flow patterns properties, turbulent kinetic energy, flow resistance, and the Darcy roughness. The study shows that it is feasible to improve the hydraulic behaviors of a stepped spillway if appendance elements are added.

In the paper "Experimental Characterization of Air Entrainment in Rectangular Free Falling Jets" [9], several flow and air-water parameters such as the phase change spatial distribution, air-water phase change of frequency, bubble chord length, turbulent intensities, and spectral analyses were successfully determined in rectangular free-falling jets using a conductivity phase detection probe. The paper highlights how a better knowledge of the air entrainment mechanism in rectangular free-falling jets will allow hydraulic engineers to know the flow characteristics of the impingement jets into the plunge pools.

The article "Three-Dimensional Flow of a Vortex Drop Shaft Spillway with an Elliptical Tangential Inlet" [10] analyzes hydraulic characteristics of vortex drop shaft (VSD) spillways using physical model experiments and a computer fluid dynamics (CFD) model. Considering that the eco-friendly VDS has become an important research hotspot in the field of flood discharge and energy dissipation, the current work can provide useful insights for future research and application of similar engineering approaches.

The paper "The Use of a Microscale Physical Model to Simulate Bankfull Discharge in the Lower Reaches of the Yellow River" [11] explores the benefits of using microscale physical models (MSPMs) to analyze flood planning in large basins. The model has different scales in the longitudinal, transversal, and vertical direction and was employed to understand flooding processes in an $800 \mathrm{~km}$ reach of the Chinese Lower Yellow River. The authors show that resistance model similarity adequately describes the relationship between the model and the prototype bankfull discharge, and with the assimilated numerical model of the Lower Yellow River reach.

In the paper "Velocimetry Based on Self-Generated Surface Wave Patterns" [12], an innovative image analysis technique was applied to quantify the average velocity of a water stream by introducing an artificially created surface disturbance. The angle of the V-shaped wake pattern created by the object decreased with the increase of the velocity. The proof-of-concept experiments presented in this paper are usable to quantify the velocity based on the wake angle is only influenced by the shape of the object geometry and its submergence. The authors suggest that the proposed method is relatively inexpensive and robust to estimate water flow velocities.

The article "An Augmented Reality Facility to Run Hybrid Physical-Numerical Flood Models" [13] presents a novel installation which extends the concept introduced by the well-known Augmented Reality-SandBox (AR-Sandbox) module. It consists of a physical scale topography built in sandbox, a scanner to generate in real time a digital terrain model (DTM), which serves as a basis for the simulation of overland flow using professional hydraulic software Iber+. A key point of the facility is that is conceived for both educational and professional uses.

In the paper "Oblique Wave Attack on Rubble Mound Breakwater Crest Walls of Finite Length" [14], a method to account for the maximum loads acting on finite length 
crest walls of rubble mound breakwaters has been developed using data gathered from a physical model. The main advantage of the proposed method is that it considers that maximum loading does not occur at the same instance over the entire length of the crest wall for oblique waves; thus, it does not overestimate loadings as conventional methods applied for oblique waves approach.

The article "Prediction of Mean Wave Overtopping Discharge Using Gradient Boosting Decision Trees" [15] develops an innovative machine learning method-gradient boosting decision trees-to predict mean wave overtopping discharges over coastal structures such as dikes, breakwaters, and promenades. The model, trained with CLASH wave overtopping database, is shown to outperform an existing neural network models by reducing the error on the prediction by a factor of 2.8. A key feature of the model is that it provides realistic trends and behave regularly in regions of the input parameter space with little or no data coverage.

The featured paper "Small-Scale Study of Mooring Line Tension Thresholds Based on Impulsive Load Analysis during Big Floating Structure Operation and Commissioning" [16] deals with the optimization of multi-floater systems linked by cables used to reduce the installation costs of offshore substructures. The work analyzes cable load during physical model simulation of a DEMOGRAVI3 installation procedure applying statistical and signalprocessing methods. The authors describe a method to define the maximum load threshold for a given mooring line setup in order to avoid snap loads.

The editor's choice article "Zonation of Positively Buoyant Jets Interacting with the Water-Free Surface Quantified by Physical and Numerical Modelling" [17] presents the evolution of positively buoyant jets with non-intrusive techniques-particle image velocimetry (PIV) and laser-induced fluorescence (LIF)—by analyzing four physical tests in their four characteristic zones,: the momentum dominant zone (jet-like), momentum to buoyancy transition zone (jet to plume), buoyancy dominant zone (plume-like), and lateral dispersion dominant zone. The physical model results were used to evaluate the performance of different numerical models. The paper highlights the main drawbacks and benefits of the most common semiempirical and computer fluid dynamics (CFD) modeling approaches used to characterize buoyant jets.

In the paper "Variation of Coefficient of Friction and Friction Head Losses Along a Pipe with Multiple Outlets" [18], a physical model has been built to simulate the flow in a pipe with multiple outlets in order to examine the existing methodologies for estimation of the friction head losses, and to propose a new method based on the experimental data. A key recommendation of the work is to consider some geometrical and physical parameters of the pipe system (outlet spacing, ratio of the area of the outlet with the main pipe, friction) to properly evaluate head losses.

The article "Study on Flow Velocity during Wheeled Capsule Hydraulic Transportation in a Horizontal Pipe" [19] analyzes experimental results and hydraulics theory in a wheeled capsule transported in the straight pipe. Radial and circumferential velocity distributions are derived from a particle image velocimetry dataset. The authors suggest that the paper's results can provide the theoretical basis for optimizing structural parameters of the wheeled capsule system.

The paper "The Wall Stress of the Capsule Surface in the Straight Pipe" [20] studies the shear stress distribution on capsule surfaces in stationary flows using the physical model presented in Yang and Ma [21]. The work highlights the importance of the different stress components on the capsule, showing that Reynolds stress cannot be neglected due to water-flow turbulence.

The article "Development and Calibration of a New Dripper-Based Rainfall Simulator for Large-Scale Sediment Wash-Off Studies" [21] presents a new drop-forming rainfall simulator as a tool for analyzing urban wash-off processes under controlled conditions. Different rainfall intensities can be generated in the model built at the Universidade da Coruña facilities, with a realistic raindrop size and velocity distributions. The paper 
highlights the importance of these rainfall characteristics as key factors affecting particle detachment and transport in overland flows.

In the paper "Sediment Morphology and the Flow Velocity Field in a Gully Pot: An Experimental Study" [22], particle image velocimetry (PIV) and laser doppler anemometry (LDA) measurements in a scale 1:1 gully were acquired to quantify the effects of gully pot geometry, flow discharge, sand trap depth, and sediment bed level on the flow field and subsequently the settling and erosion processes of sediments beds. The article highlights that the morphology dynamics of the sediment bed significantly influences the flow pattern and the removal efficiency, prohibiting the conceptualization of a gully pot as a completely mixed reactor.

Finally, the article "SewerSedFoam: A Model for Free Surface Flow, Sediment Transport, and Deposited Bed Morphology in Sewers" [23] aims to bridge the gap in the detailed modelling of flow and sediment process interactions in sewers through the development of a computer fluid dynamics (CFD) model developed on the OpenFOAM framework. SewerSedFoam models the impacts of sediment deposition and erosion on flow velocity by using dynamic mesh deformation to capture the movement of the deposited bed and its morphology. Although the functionality of the overall model is promising, the validation of a large magnitude sediment erosion events has been limited by the availability of granular datasets in existing case studies. Thus, a key recommendation of the authors is to develop specific sediment erosion and transport experiments in sewer conditions.

This Special Issue highlights some of the most ongoing approaches of physical models in hydraulic engineering. We would like to emphasize the different measurement techniques and numerical approaches being used by the authors of the papers. To conclude, we also would like to acknowledge the work of the reviewers and the authors contributions.

Author Contributions: Writing—original draft preparation, J.A.; writing—review and editing, E.P. Both authors have read and agreed to the published version of the manuscript.

Funding: This research received no external funding.

Data Availability Statement: No new data were created or analyzed in this study. Data sharing is not applicable to this article.

Conflicts of Interest: The authors declare no conflict of interest.

\section{References}

1. IAHR BOOK-Muste, M.; Lyn, D.A.; Admiraal, D.M.; Ettema, R.; Nikora, V.; Garcia, M.H. Experimental Hydraulics: Methods, Instrumentation, Data Processing and Management, IAHR Monograph; CRC Press/Balkema: London, UK, $2017 ;$ p. 456.

2. Valero, D.; Schalko, I.; Fiedrich, H.; Abad, J.D.; Bung, D.B.; Donchyts, G.; Felder, E.; Ferreira, R.M.L.; Hohermuth, B.; Kramer, M.; et al. Pathways Towards Democratization of Hydro-Environment Observations and Data. IAHR White Paper Series, Issue 1. 2021. Available online: https:/ / www.iahr.org/library/infor?pid=8934 (accessed on 8 July 2021).

3. HYDRALAB+ Adapting to Climate Change. Available online: https://cordis.europa.eu/project/id/654110/es (accessed on 8 July 2021).

4. Co-UDlabs. Building Collaborative Urban Drainage research labs communities. Available online: https://cordis.europa.eu/ project/id/101008626/es (accessed on 8 July 2021).

5. Macián-Pérez, J.; Vallés-Morán, F.; Sánchez-Gómez, S.; De-Rossi-Estrada, M.; García-Bartual, R. Experimental Characterization of the Hydraulic Jump Profile and Velocity Distribution in a Stilling Basin Physical Model. Water 2020, 12, 1758. [CrossRef]

6. Hassanpour, N.; Hosseinzadeh Dalir, A.; Bayon, A.; Abdollahpour, M. Pressure Fluctuations in the Spatial Hydraulic Jump in Stilling Basins with Different Expansion Ratio. Water 2021, 13, 60. [CrossRef]

7. Lu, Y.; Yin, J.; Yang, Z.; Wei, K.; Liu, Z. Numerical Study of Fluctuating Pressure on Stilling Basin Slab with Sudden Lateral Enlargement and Bottom Drop. Water 2021, 13, 238. [CrossRef]

8. Ghaderi, A.; Abbasi, S. Experimental and Numerical Study of the Effects of Geometric Appendance Elements on Energy Dissipation over Stepped Spillway. Water 2021, 13, 957. [CrossRef]

9. Carrillo, J.; Ortega, P.; Castillo, L.; García, J. Experimental Characterization of Air Entrainment in Rectangular Free Falling Jets. Water 2020, 12, 1773. [CrossRef]

10. Yang, Z.; Yin, J.; Lu, Y.; Liu, Z.; Yang, H.; Xu, G. Three-Dimensional Flow of a Vortex Drop Shaft Spillway with an Elliptical Tangential Inlet. Water 2021, 13, 504. [CrossRef] 
11. Zhang, X.; Chen, M.; Wu, P.; Xin, F. The Use of a Microscale Physical Model to Simulate Bankfull Discharge in the Lower Reaches of the Yellow River. Water 2020, 12, 13. [CrossRef]

12. Ho, H.; Lin, Y.; Muste, M. Velocimetry Based on Self-Generated Surface Wave Patterns. Water 2020, 12, 2342. [CrossRef]

13. Puertas, J.; Hernández-Ibáñez, L.; Cea, L.; Regueiro-Picallo, M.; Barneche-Naya, V.; Varela-García, F. An Augmented Reality Facility to Run Hybrid Physical-Numerical Flood Models. Water 2020, 12, 3290. [CrossRef]

14. Mares-Nasarre, P.; van Gent, M. Oblique Wave Attack on Rubble Mound Breakwater Crest Walls of Finite Length. Water 2020, 12, 353. [CrossRef]

15. Den Bieman, J.; Wilms, J.; van den Boogaard, H.; van Gent, M. Prediction of Mean Wave Overtopping Discharge Using Gradient Boosting Decision Trees. Water 2020, 12, 1703. [CrossRef]

16. Cabrerizo-Morales, M.; Molina-Sanchez, R.; Pérez-Rojas, L. Small-Scale Study of Mooring Line Tension Thresholds Based on Impulsive Load Analysis during Big Floating Structure Operation and Commissioning. Water 2021, 13, 1056. [CrossRef]

17. García-Alba, J.; Bárcena, J.; García, A. Zonation of Positively Buoyant Jets Interacting with the Water-Free Surface Quantified by Physical and Numerical Modelling. Water 2020, 12, 1324. [CrossRef]

18. Alawee, W.; Almolhem, Y.; Yusuf, B.; Mohammad, T.; Dhahad, H. Variation of Coefficient of Friction and Friction Head Losses Along a Pipe with Multiple Outlets. Water 2020, 12, 844. [CrossRef]

19. Li, Y.; Gao, Y.; Sun, X.; Zhang, X. Study on Flow Velocity during Wheeled Capsule Hydraulic Transportation in a Horizontal Pipe. Water 2020, 12, 1181. [CrossRef]

20. Yang, X.; Ma, J. The Wall Stress of the Capsule Surface in the Straight Pipe. Water 2020, 12, 242. [CrossRef]

21. Naves, J.; Anta, J.; Suárez, J.; Puertas, J. Development and Calibration of a New Dripper-Based Rainfall Simulator for Large-Scale Sediment Wash-Off Studies. Water 2020, 12, 152. [CrossRef]

22. Rietveld, M.; de Rijke, D.; Langeveld, J.; Clemens, F. Sediment Morphology and the Flow Velocity Field in a Gully Pot: An Experimental Study. Water 2020, 12, 2937. [CrossRef]

23. Murali, M.; Hipsey, M.; Ghadouani, A.; Yuan, Z. SewerSedFoam: A Model for Free Surface Flow, Sediment Transport, and Deposited Bed Morphology in Sewers. Water 2020, 12, 270. [CrossRef] 